\title{
Designing An MBA Curriculum With AACSB In Mind
}

Virginia Anne Taylor, (Email: TaylorV@wpunj.edu), William Paterson University Martin Rudnick, (Email: RudnickM@wpunj.edu), William Paterson University

\begin{abstract}
This paper reports on our investigation of how AACSB standards can be woven into an MBA curriculum. The result is a bold move away from functional "silos" and a radical redesign using a cross-functional integrated approach. The Cotsakos College of Business's curricular requirements were examined in order to determine whether or not they addressed the pertinent issues and were suitable educational criteria for conference of the Masters of Business Administration Degree at an AACSB international school.
\end{abstract}

\section{INTRODUCTION}

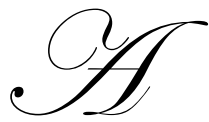

$\mathrm{s}$ an accreditation candidate our primary objective was to uncover and apply suitable AACSB standards criteria for the program design and continuous curriculum improvement for the Masters of Business Program. Our more specific goal was to compare the recommendations of AACSB standards with the then current program requirements in order to determine the relevance or lack thereof for each of the original sixty credits required for completion of the old program. We wanted to know whether they were all needed and how each course helped to meet each of the various AACSB requirements. In a mission driven framework, quality refers to the degree to which aspirations and performance are one and the same. In other words success is the extent to which a program achieves its goals. (Institutional Effectiveness-Underwood \& Cummings, AACSB 2001). The Mission of the Christos M. Cotsakos College of Business is to provide quality education in the area of business for our diversified student body. We are committed to continuous improvement as it concerns, teaching, intellectual contributions which enhance teaching and learning, and service, to the extent that it enhances the educational environment. This mission is addressed through the delivery of a dynamic curriculum that is designed to meet the changing demands of an internationally diverse and technologically oriented marketplace. Graduate Program goals and objectives are guided by the same framework as our undergraduate program, although an increased emphasis is placed on a cross functional pedagogical approach to teaching, and integrated technology across the upper core of non-waiveable courses which every student must take in residence at William Paterson.

\section{BACKGROUND}

The original MBA program required sixty credits, divided into two sections. The forty-two credit core basically reflected the undergraduate core for the BS in Business Administration. The additional twelve credits were taken within a concentration area. Alternately, a student could elect to take any four classes for a concentration in General Business. Initially a business student could apply for course waivers up to a maximum of thirty credits of the core requirements based on undergraduate work. When the college decided to apply for AACSB accreditation, the maximum waiver credits was reduced to fifteen credits in order to strengthen the curricular content and insure greater graduate level coverage of the required standards and perspectives. In 1998 at the dean's request visiting AACSB representatives held two faculty information meetings at William Paterson University. As a result a Graduate Curriculum Committee was formed and charged with an intense investigative study of the MBA program in order to recommend improvements. Problems areas considered that year included: too many classes were canceled due to low enrollment; regulations needed revision to stop students from taking regular classes as an independent study. Many classes on the books were either not offered or canceled due to low enrollment. Some students has begun to assume they would be given permission to take a class without having completed the 
prerequisite to ensure timely degree completion. In the design process for the new MBA curriculum, the faculty carefully reviewed the catalogue and eliminated prerequisites considered not really necessary for the completion of the listed courses. Therefore, out of sequence registration is not permitted. On occasion a concurrent enrollment will be considered with the approval of the MBA advisor, department chair, course leader, the professor who is teaching the course and the dean.

Next, public evidence was gathered to compare the MBA curriculum requirements of sister colleges. This research data indicated our original program was considerably longer than any of the other AACSB schools in the area. However, the committee meetings were not particularly fruitful in the attempts to eliminate any of the required course work. Inevitably new curriculum designs were suggested which enlarged rather than reduced the core requirements. It seemed every department thought more coverage in their discipline was needed in the program. To break the impasse and to prepare for Middle States Evaluations, a topics and perspectives matrix sheet was designed, distributed and tabulated to discover the amounts of AACSB standards coverage embedded in each course. Content overlap within disciplines areas was also noted. The Middle States Planning Committee had asked for new course outlines with embedded student learning outcome objectives which were required for outcomes based assessment criteria. These new outlines helped the Graduate Curriculum Committee search for content overlap and for coverage of the AACSP contextual perspectives. This process involved one on one interviews with each of course leaders to explain how the foundation standards and contextual elements we were looking for might fit into a particular course. Standard C.1: C.1.1 requires integration of the AACSB "perspectives" shown below in Figure 1. These contextual "perspectives" were new ides to most members of the faculty. Many felt there was no room in their course content to add this "extra fluff" because every minute of class time was precious and it was difficult to cover all of the necessary "real" content.

\section{Figure 1}

\section{AACSB - Perspectives \\ (contextual elements of a business environment)}

- Ethical \& Global Issues

- Political. Social, Legal Influence

- Regulatory, Environmental Issues

- Technological Influence

- Demographic Diversity

The original program's theoretical basis was grounded in the belief that knowledge is good and more is better. However, we also believe each additional educational requirement should strengthen the student's knowledge base and enhance career opportunities. The theoretical basis for our curricular change was grounded in the knowledge that the tasks of entry level college graduate and MBA candidates who accepted jobs in corporations had changed with the advent of information technology. For example, the functional expert with a green eye shade and sharp pencil in charge of general ledger accounts was now somewhat redundant, made so by the ease with clerical persons without college degrees were able to perform routinized data entry tasks because computers were now programmable to handle many entry level accounting tasks. AACSB has said it is time to come out of our discipline specific silos and teach students to integrate knowledge across the curriculum. At our annual stakeholders' conferences business leaders and alumnae have voiced similar opinions. Our contemporary MBA program is responsive to all these voices.

In 2001 we decided to take a "zero based approach" to design an MBA program with no consideration of the current course requirements. The new dean suggested pretending we had never had an MBA program. Within our mission driven approach, the first step was a discussion and resolution of the design objectives for the new program. These are illustrated in Figure 2. 


\section{Figure 2}

\section{Program Design Objectives}

- Competitive Length - Maximum 48 credits

- Cover All AACSB Perspectives

- Foundation Knowledge in 18 credits

- Disbursement of 30 credits above foundation

- Growth Oriented Program Structure

\section{OVERVIEW OF THE NEW PROGRAM}

The current MBA Program curriculum translates into a maximum of forty-eight semester hours and a minimum of thirty semesters credits for the degree depending on the student's prior educational background. Intellectual support for the cross-functional integrated approach has been based on the premises that the interdisciplinary upper core of study was needed to give our graduates a broader base for their elective courses and in order to meet the needs of corporate employers. The entire program can be completed with forty-eight credit hours with no prior business education. A maximum of eighteen lower core credit hours may be waived based on current undergraduate courses. A minimum of thirty credit hours of coursework must be completed by all students, in residency. All students must complete the entire cross-functional upper core, which consists of eighteen credit hours of coursework that integrate business related textural components with areas of core competency. This includes the followinng courses:

Statistics, MNE Environment and Operstions, Organizational Behavior \& Communications, Management Information Systems, Business, Government \& Society, and Business Policy (the capstone course).

To highlight the importance of written and oral communication skills as defined in AACSB Standard C.1:C.1.2.c, writing and speaking are critical components of the Level II, Upper Core classes in the new MBA program. For example the Organizational Behavior and Communication course was totally integrated. A business communications textbook was used to design writing and speaking exercises fitted to the organizational behavior content. The Business Government \& Society course infuses contemporary outside readings and requires written and oral commentary by students. The Business Policy course integrates readings and requires presentations. The foundation knowledge and contextual perspectives are reinforced with elective courses.. First, in order to assure graduate level academic achievement in each fundamental discipline or area of knowledge, each student who waives a foundation course is expected to select an elective in that area to demonstrate current knowledge and proficiency with the relevant work-place skills. Then, to reinforce broad contextual coverage and increase program breadth, no more that two elective courses may come from the same discipline and each student must take one elective global course. This could be an international economics, finance, accounting, or marketing course. All degree requirements must be completed within six years of acceptance into the program.

\section{DISCUSSION OF INDIVIDUAL PERSPECTIVES}

This section of the standards deals with coverage of the required AACSB contextual elements of business environment. Standard C.1.1 states that both levels of the core must provide understanding of the business context. All of the AACSB's Contextual Perspectives (shown in Figure 1) are covered at Level II, this upper core level of the new MBA Program. Since all students are required to take these classes in residence at William Paterson University, we are assured every graduate has been properly exposed to each of them. Transfer credits for these classes are not acceptable under any circumstances. Ethical and global perspectives are covered in the upper core. In addition to the particularly strong coverage in Business, Government \& Society and Multinational Business Environment courses, both the foundation and upper level accounting, economics, finance, marketing, and management courses have these components woven into the content using the professional ethics of individual disciplines. 


\section{Figure 3}

\section{MBA Program Requirements}

- Level I - Business Foundations (these may be waived)

- Level II - Integrated Upper Core (students must take WPU courses)

- Level III - Electives - global requirement (waivers may limit elective choice)

Political, Social, Legal, Regulatory Environment Issues - The Business, Government \& Society course deals with these issues with a worldwide perspective. Accounting classes discuss differences between GAAP and IAS accounting rules, while finance classes study SEC issues. Marketing and economics courses deal with trade policy and international cultural and legal issues. Demographic Diversity ' $\mathrm{s}$ impact is addressed in all the economics, management and marketing classes and stressed in the Business, Government \& Society and Multinational Business Environment courses

Technological Influence is primarily covered in the MIS course. They are emphasized in the skills classes Mathematical Methods for Business and Computers and Applications and enhanced at upper level with electives such as Marketing Research, Operations Management. Accounting and Financial Management classes use excel spreadsheets. Our new E*Trade Financial learning center has had a very positive impact on technological aspects of the MBA program. It raises exposure to technology to a new level. This spring the Investment Analysis course was taught here and in response to the student interest it generated a new finance elective, Derivative Securities and Trading Strategies was offered in the fall, 2003. In the future even the fundamental lower core course in finance will utilize the E*Trade center so that more students benefit from the advanced technology on the new Valley Road campus.

\section{Figure 4}

\section{Program's Outcome Objectives}

(things students will be able to do)

- Understand the emerging contextual perspectives of the global business environment

- Work effectively in the cross-functional teams prevalent in today's work world

- Synthesize knowledge from related disciplines to conceptualize problems \& identify best practice

- Utilize advanced technology to investigate problems and evaluate alternate solutions

\section{CONCLUSIONS}

At the Cotsakos College of Business, the E*TRADE Financial Learning Centeris one of the few trading rooms found in an academic environment. It is the hub of all electronic business information exchange and analysis for the College. Every student has exposure to the databases and hands-on training with the software that form the backbone of modern day practitioner-driven information analysis. This year we will be working on integrating SAP enterprise resource planning software modules into the upper core classes. The addition of the Russ Berrie Institute of Professional Sales expands learning opportunities for upper core electives such as Business to Business Marketing, Market Research and Independent Studies. In the spirit of continuous improvement both students and professors will be able to use the specialized research data bases. The authors hope that this work would be of interest to both other researchers who seek better understanding of the dynamics of curriculum revision and curriculum committee members who seek new evaluation methods for improving programs and seeking accreditation. This research is both interdisciplinary and applied in the sense that it affects more than one academic discipline or professional program. These findings provide a beginning step for continuous improvement of graduate educational standards. 